\title{
Fatigue assessment in welded joints based on geometrical variations measured by laser scanning
}

\author{
Gustav Hultgren ${ }^{1}$ (1) $\cdot$ Zuheir Barsoum $^{1}$
}

Received: 25 November 2019 / Accepted: 15 July 2020 / Published online: 31 July 2020

(C) The Author(s) 2020

\begin{abstract}
In the current study a method to determine the location of fracture initiation for non-load carrying fillet welds based on continuous geometry measurements is proposed. Measurements and weld quality evaluation were carried out on welded specimens using the Winteria ${ }^{\circledR}$ software qWeld. One hundred nineteen specimens were produced, scanned, and fatigue tested until failure. The fracture surfaces have been investigated in order to find the location(s) for most probable point(s) of initiation. These data were then used to fit the proposed model parameters used to predict the point of initiation. Local weld geometry measurements were extracted from the predicted fracture initiation location(s) to analyse the correlation between local weld geometry and fatigue life. It was observed that fatigue life and leg length were positively correlated and that strong correlations exist between the individual geometrical parameters with regard to location of the fatigue crack initiation.
\end{abstract}

Keywords Weld fatigue $\cdot$ Weld quality $\cdot$ Crack initiation $\cdot$ Quality assurance

\section{Introduction}

Manufacturers of loader cranes, trucks, buses and other high strength machinery are increasing the use of high strength steel in load carrying products to save weight without reducing the performance. Welded joints in such structures are often the critical factor when it comes to fatigue failure as different material and geometrical imperfections are introduced in welded joints. Geometrical defects such as undercut, cold laps, small toe radii, and geometrical discontinuities can give rise to high stress concentrations at the weld toe, which in combination with cyclic loading leads to fatigue failure.

Current research shows the importance of weld quality monitoring and assurance. High strength steel has an increased sensitivity to geometrical defects compared to mild steel, and consistency in the weld quality is therefore critical when it comes to high strength steel applications. The

Recommended for publication by Commission XIII - Fatigue of Welded Components and Structures

Gustav Hultgren

gustavhu@kth.se

1 Department of Engineering Mechanics, KTH Royal Institute of Technology, Teknikringen 8, 10044 Stockholm, Sweden correlation between the quality classifications and the fatigue properties have however shown to be weak [1-4]. Weld quality assurance in production is today mostly carried out using spot checking with analogue gauges in an audit process that is not integrated in the production line. This method has shown to be out-dated and the use of basic standard gauges needs to be investigated and improved to be representative in relation to the actual variation in production [5].

The implementation of analysis software that transforms laser line measurements of welded joints into qualitative measurements makes it possible to document larger sections of welded joints in less time than existing analogue measurement techniques [6]. The developed system ensures a repeatable method that is independent of the operator, fast and has the possibility to capture the weld geometry continuously with a high resolution. This ensures that the actual variation in weld geometry is captured. Undercuts are in design codes currently regarded as a defect or imperfection even though it in studies has proven to prolong the fatigue life under certain conditions [7]. The re-evaluation of undercuts in welded structures needs to be related to the quality output rather than the process, which makes an accurate reading of the weld geometry vital. The use of digital quality assurance systems has further been introduced into simulations to investigate the effect of the true geometry [8]. The use of linear elastic fracture mechanic simulations on the digitally measured geometry is one way of 
Fig. 1 Specimen geometry and configuration prior to cutting

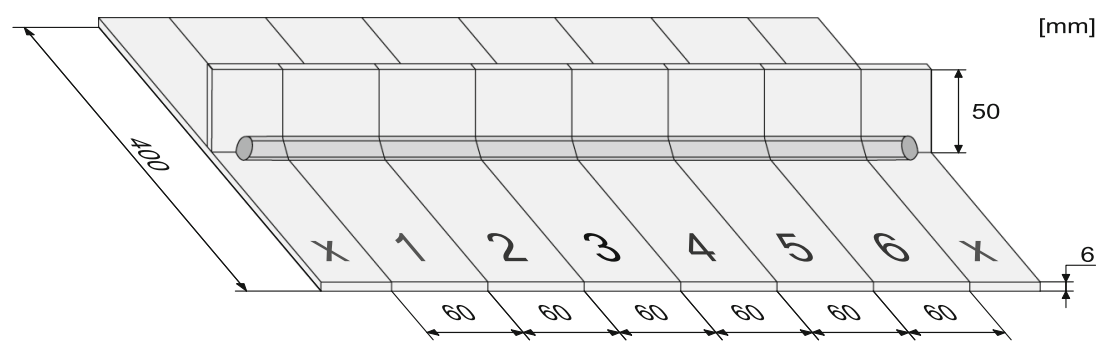

predicting the fatigue behaviour of welded joint, which has been validated to work for thicker specimens [9].

\section{Welded fatigue specimens}

This study was carried out on specimens with attached transverse stiffeners (see Fig. 1), constructed out of hot rolled highstrength steel, Strenx $700 \mathrm{MC}$, produced by SSAB. The specimens were welded using a robotic arc welder with a $1.2-\mathrm{mm}$ copper-coated solid wire. The transverse stiffener was welded using two fillet joints, one on each side of the plate. One of the two welds was post treated using high-frequency mechanical impact treatment to bound the fracture initiation to happen at the untreated side of the specimen.

\section{Specimen scanning and fatigue testing}

The as-welded fillet weld on all specimens was scanned using a Winteria® [10] weld quality measurement system, which incorporates a laser scanning device that moves the 2D measurement instrument along the weld to capture the complete $3 \mathrm{D}$ geometry. The system records the weld geometry in each profile with a resolution of 1280 pixels and the movement of the actuator at $5 \mathrm{~mm} / \mathrm{s}$, which with a sampling speed of $100 \mathrm{~Hz}$ gives a $50-\mu \mathrm{m}$ resolution in the travelling direction. The high

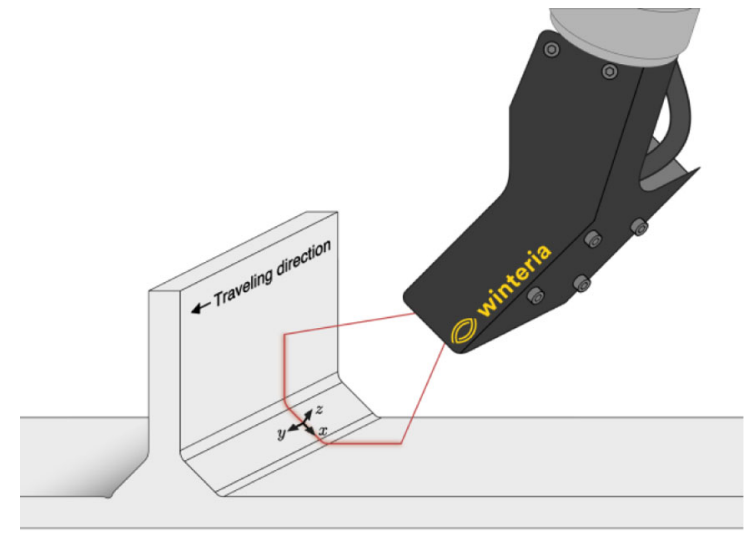

(a) Scanning setup resolution used in the travelling direction is a postulation for the work as little research has been conducted regarding the resolution needed to detect different types of weld defects. The scanning is graphically presented in Fig. 2, where the local coordinate system is displayed, together with a reconstructed 3D image of the weld surface.

The profiles captured by the laser measurement device were processed using the qWeld system from Winteria ${ }^{\circledR}$. The system breaks down each captured profile into welldefined geometrical parameters that are verified according to ISO 5817 [11]. The values of these parameters can then be used to classify the quality of each weld according to standards. This work focuses on the correlation between the relative change in local weld geometry and the location of fatigue crack initiation. Four parameters are used to construct an algorithm to determine the fracture initiation location, all concerning the local weld geometry defining the load carrying toe of the weld: leg length, weld toe radius, undercut and weld toe angle, as presented in Fig. 3.

The specimens were fatigue tested after laser scanning at two load levels of $180 \mathrm{MPa}$ and $355 \mathrm{MPa}$ at constant amplitude and at a stress ratio of 0.1 . The fracture surfaces of each specimen were investigated in order to determine the most probable fracture initiation site(s). High-resolution images were taken of all surfaces to document the patterns and to mark out the visible defects on the images themselves. Two examples of the recorded fracture surfaces can be seen in

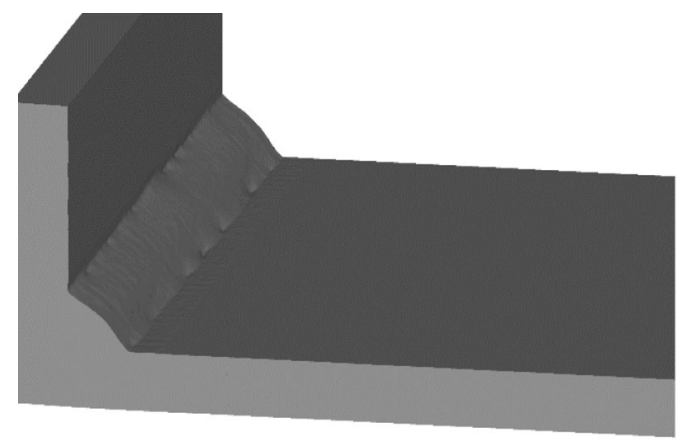

(b) Reconstructed weld surface

Fig. 2 Schematic setup of weld scanning procedure together with reconstructed weld surface. a Scanning setup. b Reconstructed weld surface 
Fig. 3 Parameters used in the their respective definitions presented algorithm together with

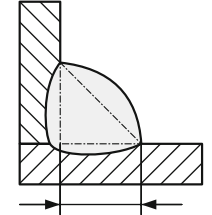

Leg length
Figs. 4 and 5. Beach marks and ratchet marks were the main lead in locating the position(s) for initiation. An uncertainty factor was introduced when determining the fracture initiation site(s) to account for the measurement uncertainty. The growth direction was backtracked using the beach marks, and the ratchet marks indicated the number of initiated cracks and to what extent they dominated the fracture. The specimens at hand had negligibly few detected welding defects, such as cold laps, so geometrical weak points were used to further pinpoint the exact location(s) of initiation. The plausible point(s) of initiation could be determined for approximately $80 \%$ of the fracture surfaces investigated of the total number of 119 specimens.

\section{Prediction of fatigue crack initiation}

Welds produced with gas metal arc welding where filler material is incorporated generally produce stochastic variations in the bead geometry along the weld seam. This is a direct consequence of the relative changes in arc voltage and size of the metal droplets added to the melt, to mention two of the input factors in the welding process. The variation in bead geometry along the weld seam gives rise to dissimilarities in the stress distribution, causing locations where crack growth conditions are more favourable, and the risk of fracture initiation is higher. The most critical locations might therefore not be located where the absolute value of individual geometrical parameters is considered weakest; it might instead be where the maximum relative deviation of the parameters is located. This work considers both cases to investigate, which one is the most influential when it comes to fracture initiation. An algorithm has been developed that uses the geometrical parameters, shown in Fig. 3, to investigate how the local change in each parameter is deviating from the global change in weld geometry, as illustrated in Fig. 6.

The aim of the proposed algorithm is to investigate the most probable point(s) of initiation for each individual

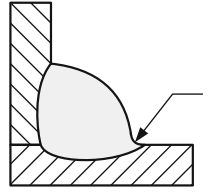

Toe radius

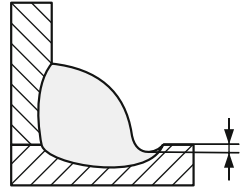

Undercut

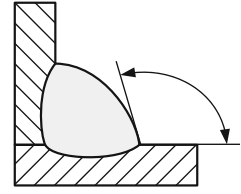

Toe angle specimen. The decision was therefore taken to rescale all the parameter arrays containing the local deviations of the weld geometry so that relative changes are investigated rather than exact changes. The relative change for each parameter is then combined using a regression model to extract an equivalent function output that represents a fracture initiation function. The maxima of this function output represent then the most plausible fatigue crack initiation sites along the weld seam. All local peaks that are above a specific threshold are regarded as equally critical to incorporate the statistical uncertainty, when several peaks that are almost equally critical exist. The threshold limit is defined as a percentage of the maximum value in the fracture initiation array; all maximum peaks above this limit are extracted for further testing, as seen in Fig. 7.

Few standardized regression fitting processes can be used to investigate the contributions of each parameter, as the output value itself is not the value of interest but instead its position in the array. This is then compared with the visually predicted point(s) of initiation. The distance between these two points is then used to determine if the prediction is regarded as correct or not. The permitted distance is determined by the accuracy in the visual prediction and how well the surface and scanning data can be correlated; in this case a distance of $1 \mathrm{~mm}$ has been used as the limit distance. This approach prohibits the use of gradient-based fitting models. An iterative method is therefore developed to fit the regression parameters so that the fracture initiation function can correctly predict the initiation location on as many specimens as possible. This is however a computationally time-consuming task, which is the reason why a linear regression model has been chosen.

\subsection{Influence of moving averages and regression parameter fitting}

The parameters in the proposed algorithm are fitted using a training group consisting of $90 \%$ of the specimens from the whole population where the locations of fracture initiation

Fig. 4 Fracture surface of specimen 8

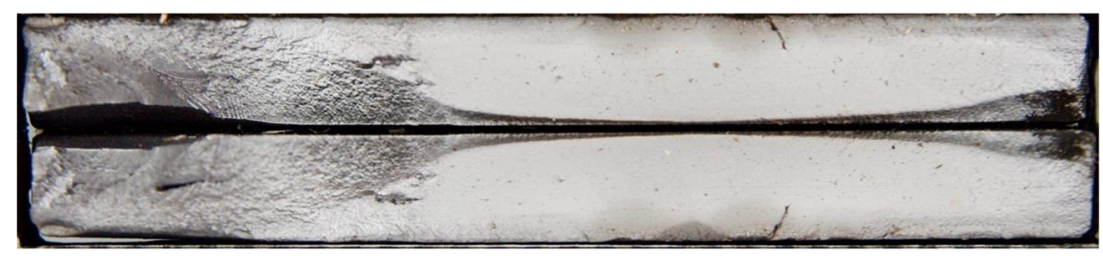


Fig. 5 Fracture surface of specimen 42

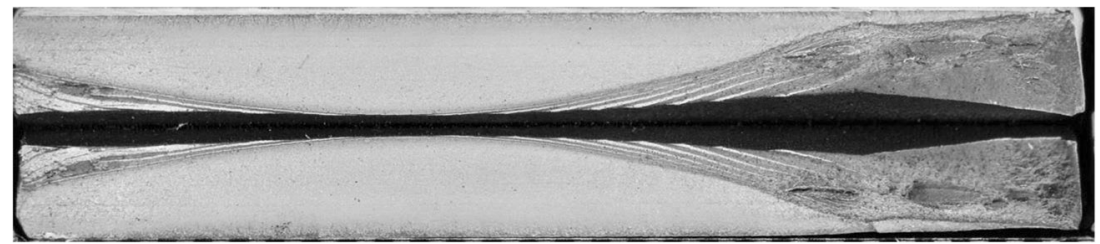

could be visually found. The method for fitting the regression parameters is tested for different combinations of distances to average the local and global measurement data over, to investigate the influences of these distances. The results are measured in correctness percentage, which indicates the percentage of specimens where the initiation locations were correctly predicted. The final, converged set of values for the regression parameters was then tested on the remaining $10 \%$ of specimens (validation group) to investigate the applicability of the model. The results from the fittings are shown in Fig. 8. It is clear that there are regions with distance combinations that yield better results with higher correctness levels; these locations have predicted the initiation(s) locations with a hit rate above $90 \%$. The validation however indicates that the regression fittings had better applicability on local average distances wider than $1.18 \mathrm{~mm}$. The most optimum region for the

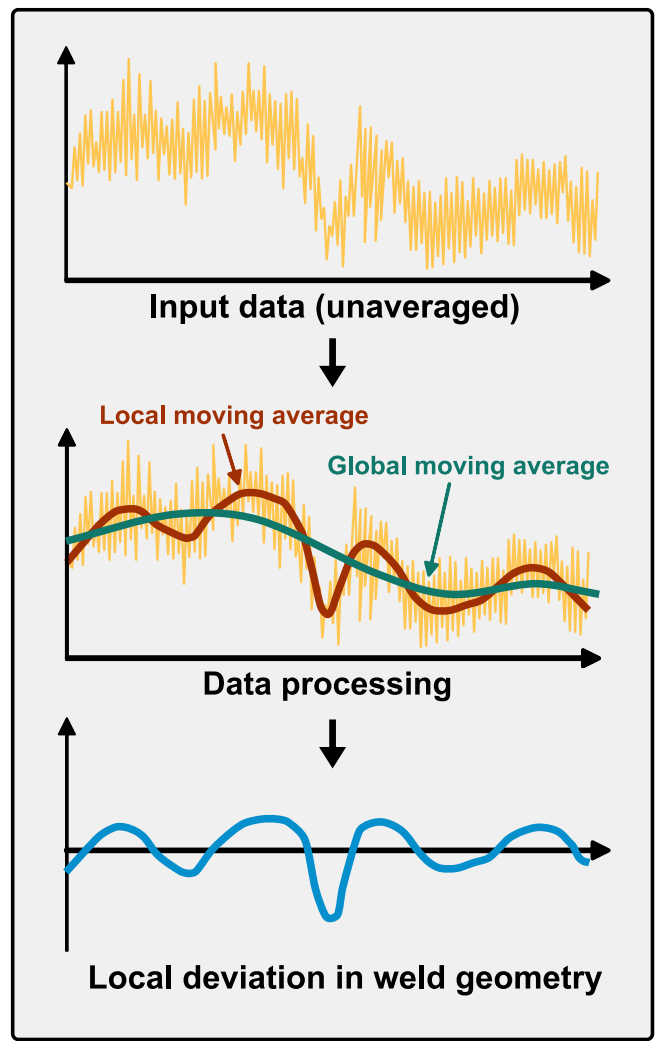

Fig. 6 Schematic representation of the data processing executed to calculate the local deviations in weld geometry training group does at least work for $80 \%$ of the specimens in the validation group, and the model is therefore regarded a good fit on the specimens investigated.

The training and validation results are combined, and the parameter combinations that resulted in the two highest correctness levels were further examined to investigate the parameter contributions to the fracture initiation function. Figure 9 shows the extracted values for the two distances to average over as well as the spread in the regression parameters, which can be regarded as the influence of each parameter array on the initiation location. Leg length has the highest contribution to the proposed algorithm closely followed by the weld toe angle. The weld toe radius as well as the undercut has less contribution when it comes to fracture initiation for the specimens investigated.

\section{Fatigue life}

The locations extracted by the algorithm have been further processed in order to investigate the relation between local weld geometry and fatigue life. A local mean value of each parameter is therefore calculated based on the data in the near region around the predicted point(s) of initiation. These mean values are then compared with each other and to the fatigue life for all the specimens that the algorithm correctly predicted the initiation location(s) for. The correlation matrix for the larger mass of specimens tested at $355 \mathrm{MPa}$ is presented in Fig. 10.

Further analyses were carried out on the local geometry using principal component analysis (PCA). This dimension reduction technique makes it possible to compare all parameters using a common, new set of dimensions called the

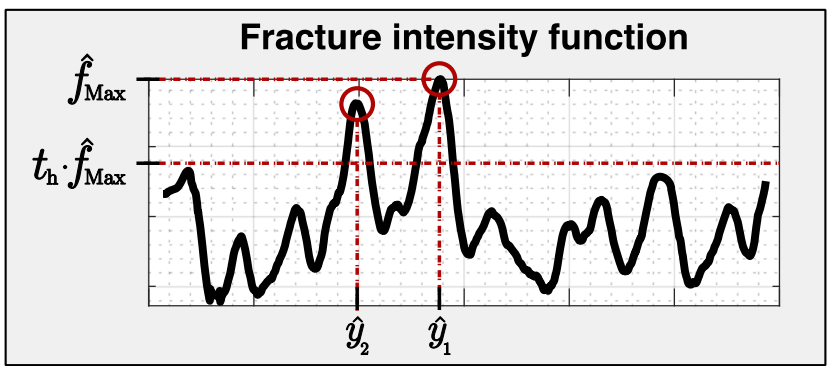

Fig. 7 Example of a fracture intensity function with two peaks above the threshold limit 


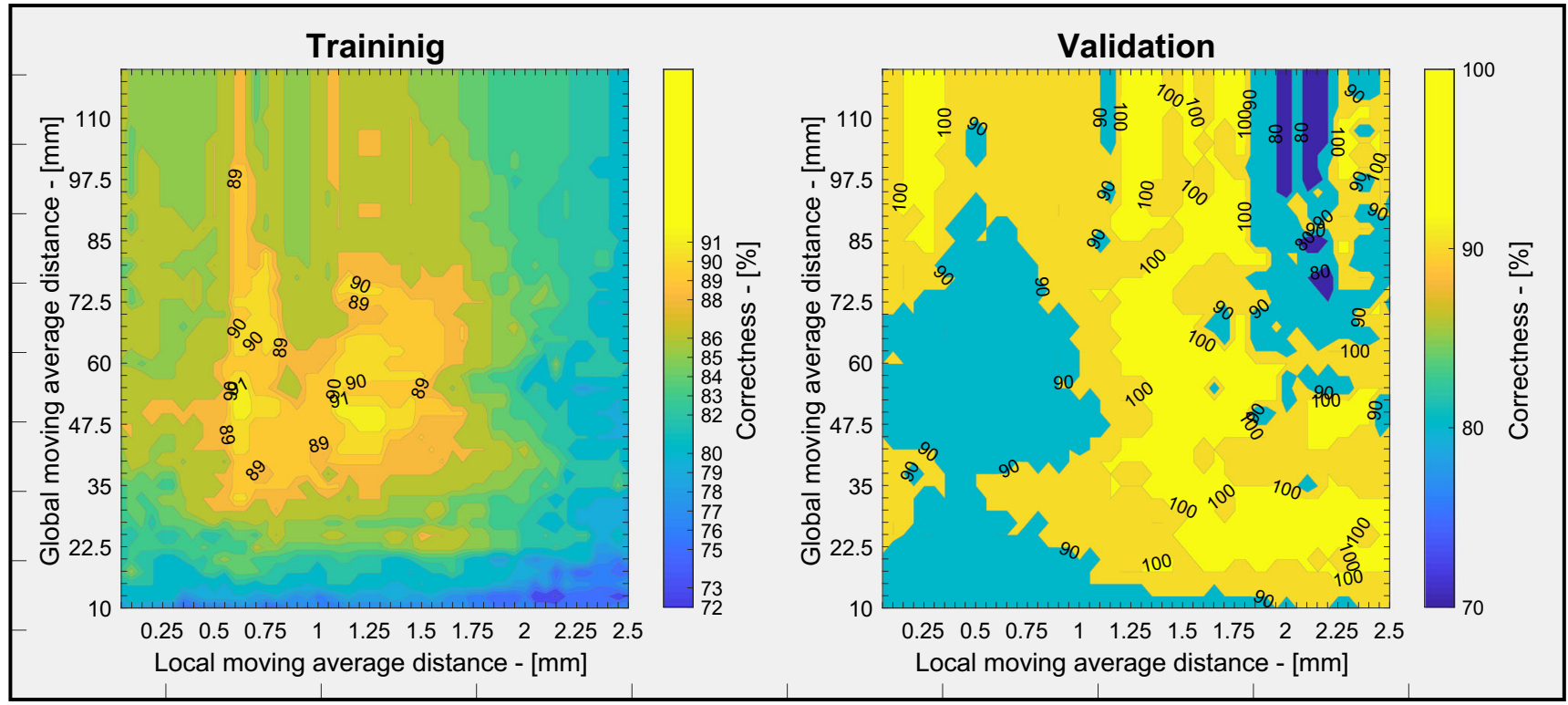

Fig. 8 Influence of the two moving averages for the training and validation groups. The bright yellow region represents the combinations with the highest number of correctly predicted initiation locations

principal components [12]. These principal components represent the directions in which the variation of each parameter is the largest. The final results of the analysis are presented in Fig. 11. A biplot shows the distribution of each parameter in its principal components. A sharp angle between two vectors indicates that there should exist a positive correlation between the parameters. Two orthogonal vectors indicate that the two effects have a low possibility of being correlated. In contrast to sharp angles, blunt angles indicate that there is a negative correlation. The biplot shows that there is high correlation between leg length and fatigue life, as the angle between these two vectors is the sharpest. Furthermore, a strong correlation can be observed between the local weld geometry parameters: weld toe radius and weld toe angle. However, no correlation can be observed between the local weld geometry parameter undercut and the fatigue life. One possible explanation could be due to the overall lack of undercut of a substantial magnitude, which makes the influence of the undercut less significant as it only was found in some of the specimens analysed.

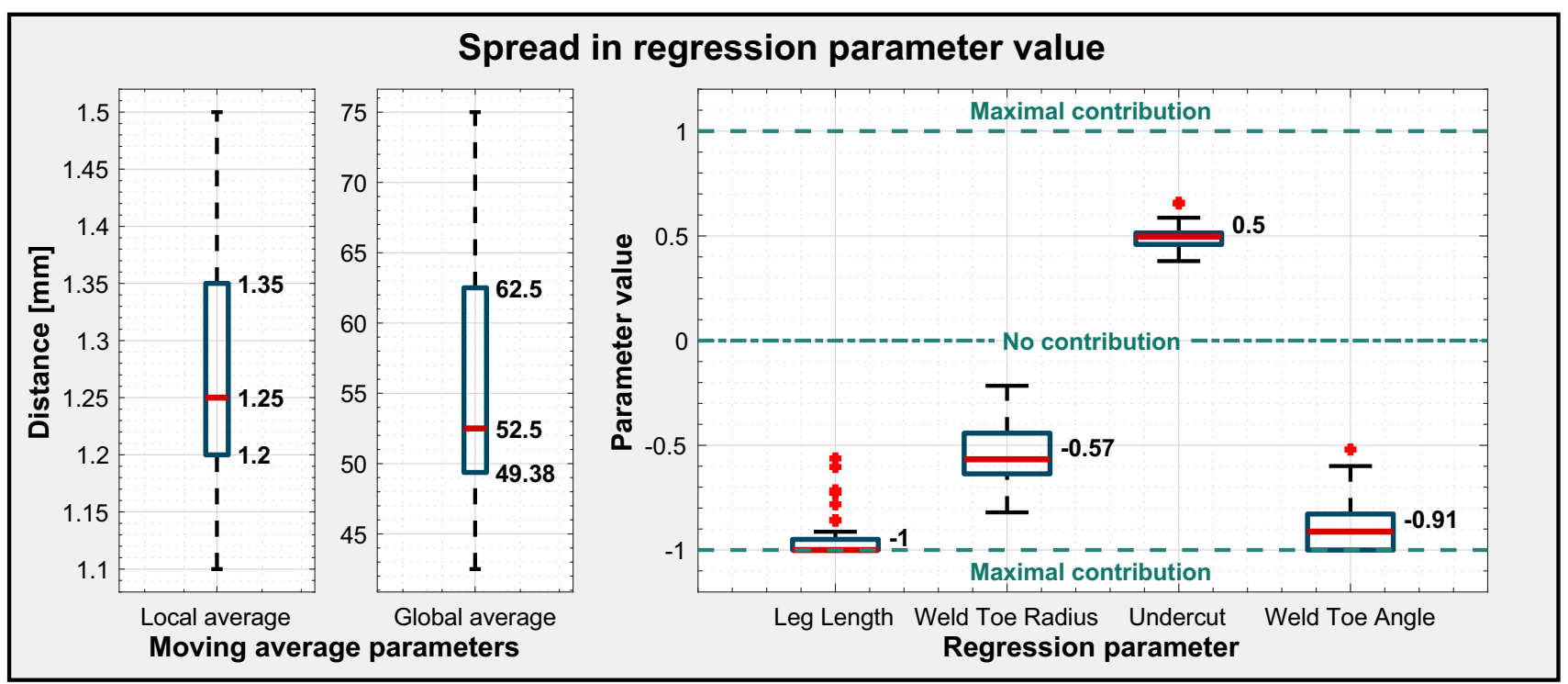

Fig. 9 Distribution in the values of the regression parameters for the most accurate fittings of the developed algorithm 


\section{Correlation matrix for fracture initiation location}

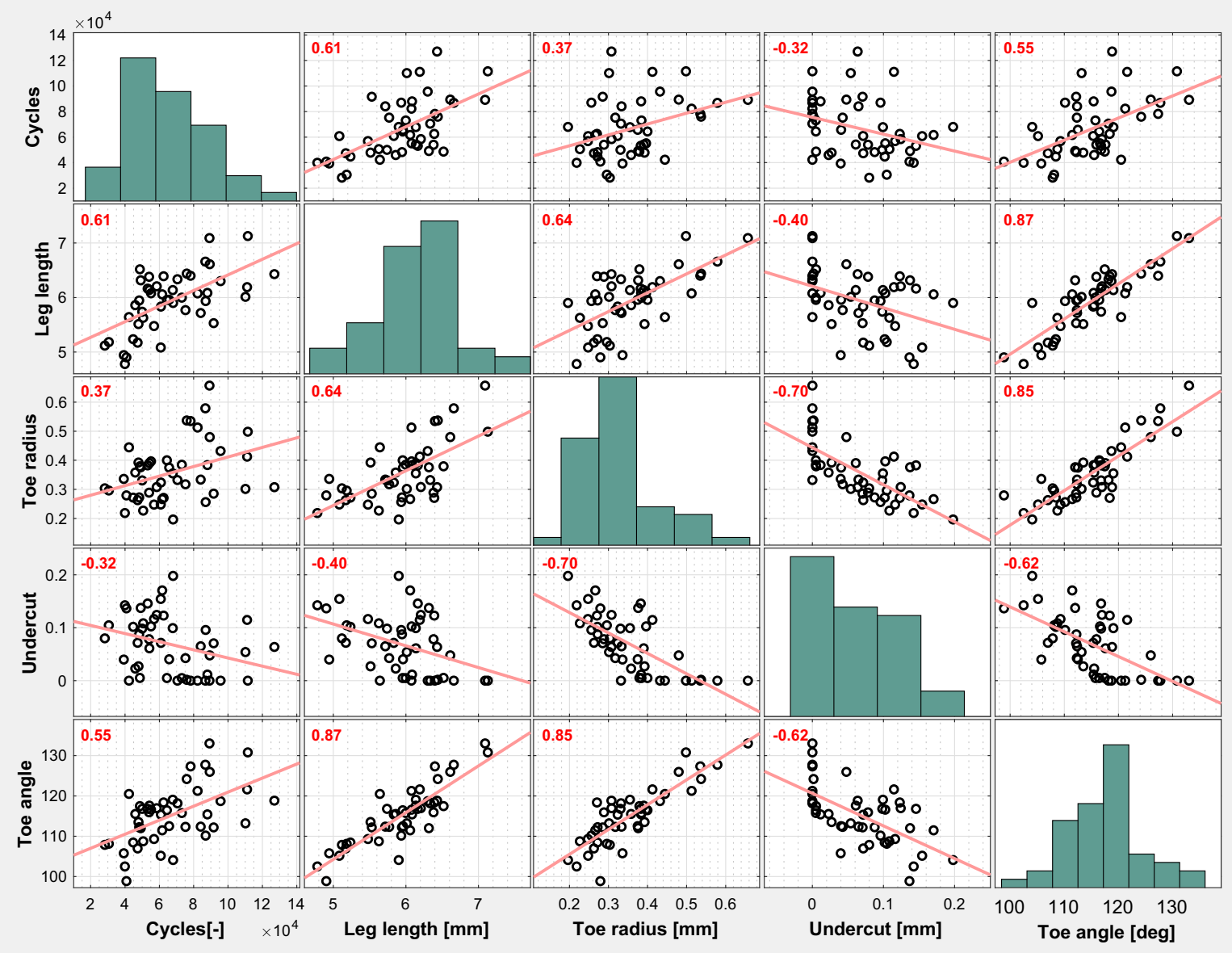

Fig. 10 Correlation matrix over the fatigue life and local weld geometry

\section{Discussion and concluding remarks}

In the current study a method to determine the location of fracture initiation for non-load carrying fillet welds, based on continuous geometry measurements, is proposed. The reason for the microscope investigation was to estimate the frequency of occurrence of different surface defects and fracture surfaces on a macrolevel. It is recommended for further work that the accuracy of the laser scanning Winteria ${ }^{\circledR}$ system, for prediction of the crack initiation sites, should be cross validated with high-quality scanning electron microscope images from the fracture surfaces.

Based on fatigue testing and local weld geometry evaluation and analyses, the following observations and conclusions are made:

- The plausible point(s) of initiation could be determined for approximately $80 \%$ of the fracture surfaces investigated of the total number of 119 specimens.
- It is clear that there are regions with distance combinations that yield better results with higher correctness levels; these locations have predicted the initiation locations with a hit rate above $90 \%$.

- Leg length has the largest contribution to the proposed algorithm closely followed by the weld toe angle. The weld toe radius and the undercut have less contribution when it comes to fracture initiation for the specimens investigated.

- The correlation analysis of the geometrical parameters at the fatigue crack initiation locations implies a pattern of correlation. There might therefore exist interaction effects that yield higher influence on the location of the fatigue fracture initiation than the linear sum of the individual parameters. 
Fig. 11 Principal component analysis of the local weld geometry

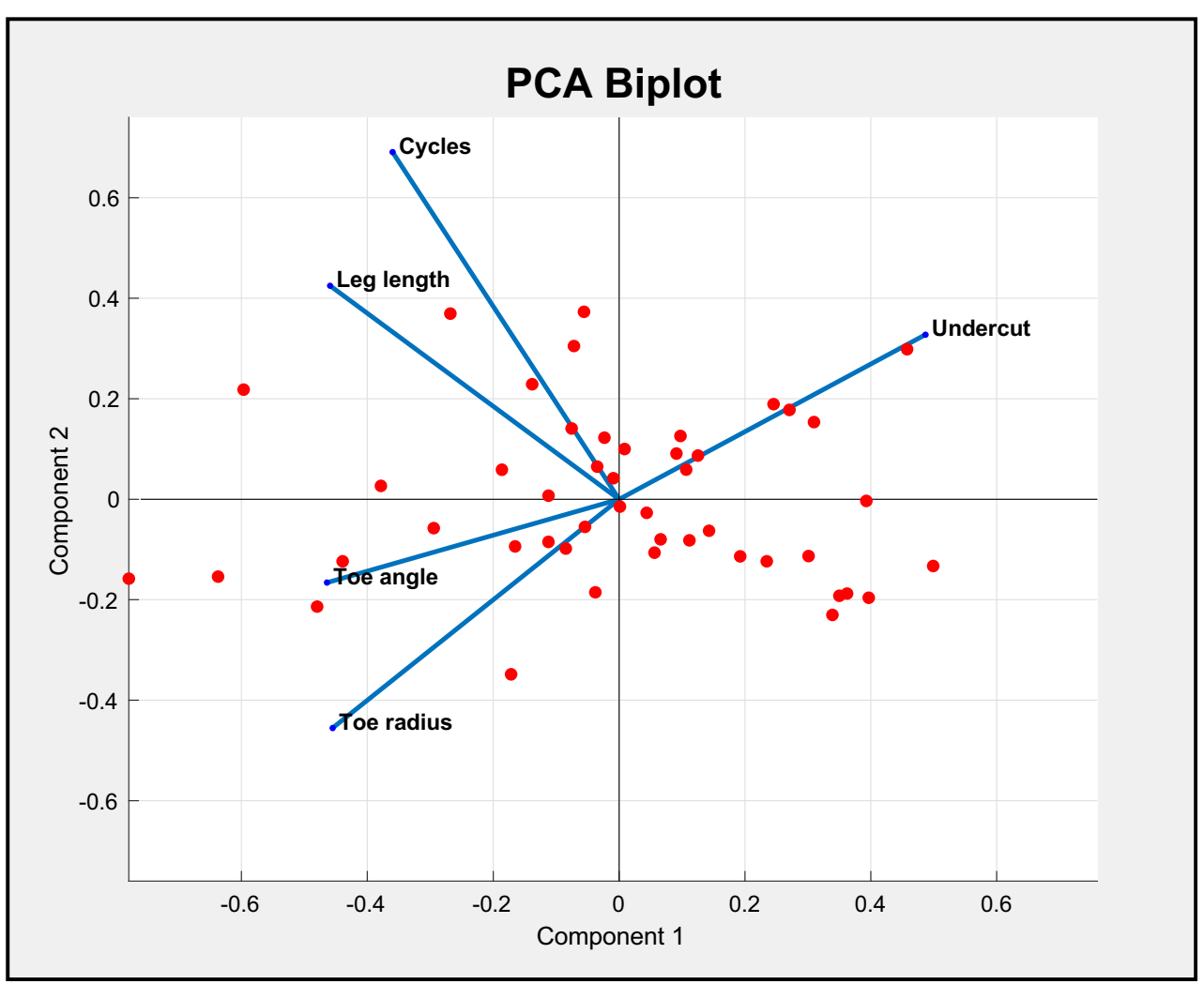

Acknowledgments Open access funding provided by Royal Institute of Technology. The authors would like to acknowledge the FATscat project members that shared the data and specimens that they had produced and tested in the FATscat project.

Funding information The authors received funding support from funding agency Vinnova through the VariLight project (contract number: 201603363).

Open Access This article is licensed under a Creative Commons Attribution 4.0 International License, which permits use, sharing, adaptation, distribution and reproduction in any medium or format, as long as you give appropriate credit to the original author(s) and the source, provide a link to the Creative Commons licence, and indicate if changes were made. The images or other third party material in this article are included in the article's Creative Commons licence, unless indicated otherwise in a credit line to the material. If material is not included in the article's Creative Commons licence and your intended use is not permitted by statutory regulation or exceeds the permitted use, you will need to obtain permission directly from the copyright holder. To view a copy of this licence, visit http://creativecommons.org/licenses/by/4.0/.

\section{References}

1. Barsoum Z, Samuelsson J, Jonsson B, Björkblad A (2012) Fatigue design of lightweight welded vehicle structures: influence of material and production procedures. J Eng Manuf 226(10):1736-1744

2. Jonsson B, Samuelsson J, Marquis G (2012) Development of weld quality criteria based on fatigue performance. Weld World 56(11):53-169

3. Barsoum Z, Samuelsson J (2006) Fatigue assessment of cruciform joints welded with different methods. Steel Res Int 77(12):882-888
4. Barsoum Z, Jonsson B (2010) Influence of weld quality on the fatigue strength in seam welds. Eng Fail Anal 18:971-979

5. Hammersberg P, Olsson H (2010) Statistical evaluation of welding quality in production. Swedish Conference on Light Weight Optimized Welded Structures

6. Stenberg T, Barsoum Z, Åstrand E, Ericson Öberg A, Schneider C, Hedegård J (2017) Quality control and assurance in fabrication of welded structures subjected to fatigue loading. Weld World 61: 1003-1015

7. Åstrand E, Stenberg T, Jonsson B, Barsoum Z (2016) Welding procedures for fatigue life improvement of the weld toe. Weld World 60:573-580

8. Alam M, Barsoum Z, Jonsén P, Kaplan A, Haggblad H (2010) The influence of surface geometry and topography on the fatigue crackingbehaviour of laser hybrid welded eccentric fillet joints. Appl Surf Sci 256:1936-1945

9. Stenberg T, Barsoum Z, Hedlund J, Josefsson J (2019) Development of a computational fatigue model for evaluation. Weld World 63:1771-1785

10. Winteria AB, winteria.se , Nordenholm 104, 82493 Hudiksvall, Sweden

11. ISO 5817 Welding - Fusion-welded joints in steel, nickel, titanium and their alloys (beam welding excluded) - quality levels for imperfections. International Organization for Standardization, Geneva, Switzerland

12. Bisgaard S, Kulahei M (2006) Quality quandaries: the application of principal component analysis for process monitoring. Qual Eng 18:95-103

Publisher's note Springer Nature remains neutral with regard to jurisdictional claims in published maps and institutional affiliations. 